\title{
BRAF Inhibitors and Radiation Do Not Act Synergistically to Inhibit WT and V600E BRAF Human Melanoma
}

\author{
LISA WALTER and LUCIE HEINZERLING
}

Department of Dermatology, University Hospital of Erlangen, Erlangen, Germany

\begin{abstract}
Background/Aim: Recent evidence suggests that melanoma patients treated with BRAF inhibitors experience radiosensitization with an increased frequency of sideeffects. This could also imply increased effectiveness when treating melanoma. Materials and Methods: To test whether the BRAF inhibitors dabrafenib and vemurafenib together with ionizing radiation more effectively inhibit melanoma cells, primary human melanoma tumor cell lines expressing wild-type (WT) or mutant V600E BRAF were analyzed by cell survival, cell death, and cell-cycle testing. Results: All melanoma cell lines examined were radioresistant in these assays. BRAF inhibitor treatment alone suppressed cell survival more effectively than radiation in all the mutant V600E BRAF cell lines, and vemurafenib, but not dabrafenib, also inhibited cell survival in the WT BRAF cell lines at clinically relevant concentrations. However, when cells were treated with BRAF inhibitor followed by radiation, there was no increased effect on the suppression of cell survival. Vemurafenib induced more necrosis than radiation in most melanoma cell lines, irrespective of BRAF status, but this effect was not additive with the combination treatment. $B R A F$ inhibitors and radiation had variable, but independent effects on the induction of cell-cycle arrest. Conclusion: These results suggest that BRAF inhibitors and ionizing radiation do not act synergistically to inhibit the growth of primary human melanoma cells.
\end{abstract}

Therapeutic options for patients with melanoma have been rapidly evolving. The identification of activating point mutations in the gene encoding the serine-threonine protein

Correspondence to: Lisa Walter, Department of Computer Science, Central Institute of Medical Engineering (ZiMT), FriedrichAlexander-University Erlangen-Nuremberg (FAU), Henkestr. 91, 91052 Erlangen, Germany. Tel: +49 91318526861, e-mail: lisa.ann.walter@fau.de

Key Words: Melanoma, BRAF, BRAF inhibitor, radiotherapy, V600E mutant BRAF, vemurafenib, dabrafenib. kinase BRAF in over $60 \%$ of melanomas $(1,2)$ greatly altered the treatment landscape, as small-molecule inhibitors directed against V600 mutant BRAF were subsequently developed. Mutant BRAF constitutively activates the mitogen-activated protein kinase (MAPK) pathway, increasing cell proliferation and preventing apoptosis $(1,3)$. The substitution of valine by glutamic acid at codon 600 (BRAF V600E) is the most common BRAF gene mutation in cutaneous melanoma (4-7), and the BRAF V600E-selective inhibitors vemurafenib (8) and dabrafenib (9) have been shown to reduce the kinase activity of this protein.

Vemurafenib $(10,11)$ and dabrafenib (12) are currently used as standard treatment for patients with metastatic $B R A F$ V600-mutated melanoma. Although overall survival is improved with BRAF-inhibitor therapy alone and in combination with mitogen-activated protein kinase kinase (MEK) inhibitors (13), drug resistance remains a major factor that limits BRAF-inhibitor clinical efficacy, and strategies to overcome this will improve clinical outcome. BRAF inhibitors have been reported to induce radiosensitization in melanoma patients, with vemurafenib increasing radiosensitivity more than dabrafenib and an increased frequency of side effects (14). Currently, there is no standard approach to the concomitant use of BRAF inhibitor therapy with radiotherapy. The aim of this study was to investigate whether a potential synergy between BRAF inhibitor therapy and radiotherapy on melanoma cells exists. Primary human melanoma cell lines expressing WT or V600E mutant BRAF were treated with BRAF inhibitors, with or without MEK inhibitors, followed by ionizing radiation, and cell survival was analyzed. Cell death and cell cycle responses were also evaluated following treatment with BRAF inhibitors and radiation.

\section{Materials and Methods}

Cell lines and BRAF mutational analyses. Primary human melanoma cells (from primary tumors) were collected in the Department of Dermatology of the University Hospital of Erlangen following approval by the institutional review board. Single cell suspensions were generated by digesting tissue samples with collagenase (Sigma, 
Table I. Clinically relevant human plasma concentrations and experimental concentrations used in the present study for BRAF inhibitors vemurafenib and dabrafenib and MEK inhibitors trametinib and cobimetinib.

\begin{tabular}{lccc}
\hline Drug name (marketed as) & Experimental concentration & Plasma concentration & Reference for plasma concentration \\
\hline Vemurafenib (Zelboraf ${ }^{\circledR}$ ) & $60 \mu \mathrm{M}$ & $100 \mu \mathrm{M}$ & $(20)$ \\
Dabrafenib (Tafinlar ${ }^{\circledR}$ ) & $1 \mu \mathrm{M}$ & $2 \mu \mathrm{M}$ & $(21)$ \\
Trametinib (Mekinist $^{\circledR}$ ) & $30 \mathrm{nM}$ & $40 \mathrm{nM}$ & $(22)$ \\
Cobimetinib (Cotellic $^{\circledR}$ ) & $300 \mathrm{nM}$ & $500 \mathrm{nM}$ & $(23)$ \\
\hline
\end{tabular}

Darmstadt, Germany), hyaluronidase (Sigma, Darmstadt, Germany), and DNAse (Roche, Mannheim, Germany). Continuous cell culture was performed in RPMI (Lonza, Cologne, Germany) supplemented with $20 \%$ fetal calf serum (FCS, PAA, Freiburg, Germany), Lglutamine (2 mM, Lonza), HEPES (PAA), pyruvate (PAA), nonessential amino acids (PAA), and gentamicin $(20 \mu \mathrm{g} / \mathrm{ml}$, PAA) with 1 to 2 passages per week. To avoid changes in cell physiology over time, cells were used at a low passage number $(<10)$. For experiments, cells were cultured in RPMI supplemented with $10 \%$ FCS, L-glutamine, and gentamicin. The $B R A F$ gene in each cell line was confirmed by pyrosequencing to show the presence (V600E) or absence (WT) of the BRAF V600E mutation.

Drug treatments and radiation. Drugs were purchased from Hoelzel Diagnostika (Cologne, Germany). Stock concentrations of the BRAF inhibitors vemurafenib $(100 \mathrm{mM})$ and dabrafenib $(10 \mathrm{mM})$ and the MEK inhibitors trametinib $(10 \mathrm{mM})$ and cobimetinib $(10 \mathrm{mM})$ were prepared in dimethylsulfoxide (DMSO) and stored at $-80^{\circ} \mathrm{C}$. Cells were treated with either drug or vehicle (DMSO) for the indicated times at the concentrations listed. Ionizing radiation $(2,6$, or $10 \mathrm{~Gy})$ was generated by a General Electric Isovolt 160 with a dose rate of $4 \mathrm{~Gy} / \mathrm{min}$.

Cell survival. Cell survival assays were performed in duplicate wells in 96-well flat-bottom plates. Four hours following seeding, cells were treated with drug or vehicle, and the WST-1 assay (Roche, Mannheim, Germany) was executed at the indicated time points. Plates were read at a wavelength of $450 \mathrm{~nm}$ with a Wallac Victor 2 plate reader operated by Wallac 1420 Manager software. For radiation experiments, cells were irradiated 20 hours following drug treatment, and the WST-1 response was measured the following day.

Cell death. For analyses of cell death, cells were cultured in 6-well plates and treated with drugs 4 hours later. After 20 hours, cells were irradiated, and, after an additional day, harvested with trypsin. Early apoptotic cell death was measured by annexin V (eBioscience, Darmstadt, Germany) single-positive staining, and necrotic death was measured by propidium iodide (eBioscience, Darmstadt, Germany) positive staining according to the manufacturer's instructions. Cells were measured with a BD FACS Canto II flow cytometer operated with BD FACS Diva software. All flow cytometry analyses were performed with FlowJo Version 10 software with gating on singlet events.

Cell cycle. For cell cycle analyses, cells were treated and harvested as per the cell death analyses, but instead washed in PBS, fixed in $70 \%$ ethanol on ice for $20 \mathrm{~min}$, washed twice in PBS, and stained with propidium iodide $(50 \mu \mathrm{g} / \mathrm{ml})$ in PBS containing RNase
(20 $\mu \mathrm{g} / \mathrm{ml}$, Qiagen, Hilden, Germany). Cells were measured in a linear range with a BD FACS Canto II flow cytometer operated with BD FACS Diva software. Singlet events were gated with FlowJo Version 10 software.

Statistics. All statistical analyses were performed with IBM SPSS Statistics 20 software.

\section{Results}

Dabrafenib and vemurafenib rapidly inhibited primary human mutant V600E BRAF melanoma cells at clinically relevant concentrations. Primary human melanoma cell lines expressing wildtype BRAF (TZ05, TZ07, and TZ08) or mutant V600E BRAF (TZ02, TZ03, TZ04, and TZ06) were treated for 2 days with dabrafenib, vemurafenib, or vehicle (DMSO) at concentrations equivalent to the published plasma concentrations of melanoma patients treated with these drugs (Table I) as well as lower concentrations, which may better correspond with the amount of drug that reaches the tumor cells in vivo. Responses in the WST-1 cell survival assay showed that the mutant V600E BRAF cell lines were more sensitive to dabrafenib than the WT BRAF cell lines in the range of $10 \mathrm{nM}$ to $3 \mu \mathrm{M}$ (Figure 1A). Vemurafenib inhibited all the cell lines tested at a concentration of $60 \mu \mathrm{M}$, with all 4 mutant V600E BRAF cell lines sensitive to concentrations as low as $1 \mu \mathrm{M}$ (Figure 1B). For further experiments, the clinically relevant concentrations of $1 \mu \mathrm{M}$ for dabrafenib and $60 \mu \mathrm{M}$ for vemurafenib were used.

Subsequently, a time course of melanoma cell line responses to $B R A F$ inhibitors was established. Whereas the mutant BRAF cell lines were inhibited by dabrafenib at all time points examined, the WT BRAF cell lines showed minimal or no response (Figure 1C). The mutant V600E $B R A F$ cell lines were also inhibited by a single treatment of vemurafenib by day 1 , and this inhibition was sustained at days 2, 3, and 4 (Figure 1D). The WT BRAF cell line TZ07 showed minimal inhibition to vemurafenib, while TZ08 was inhibited $20 \%$ and TZ05 $60 \%$ by day 2, responses that were sustained until day 4 (Figure 1D).

$B R A F$ inhibitors and MEK inhibitors reduced melanoma cell survival more effectively than radiation. Based on the 

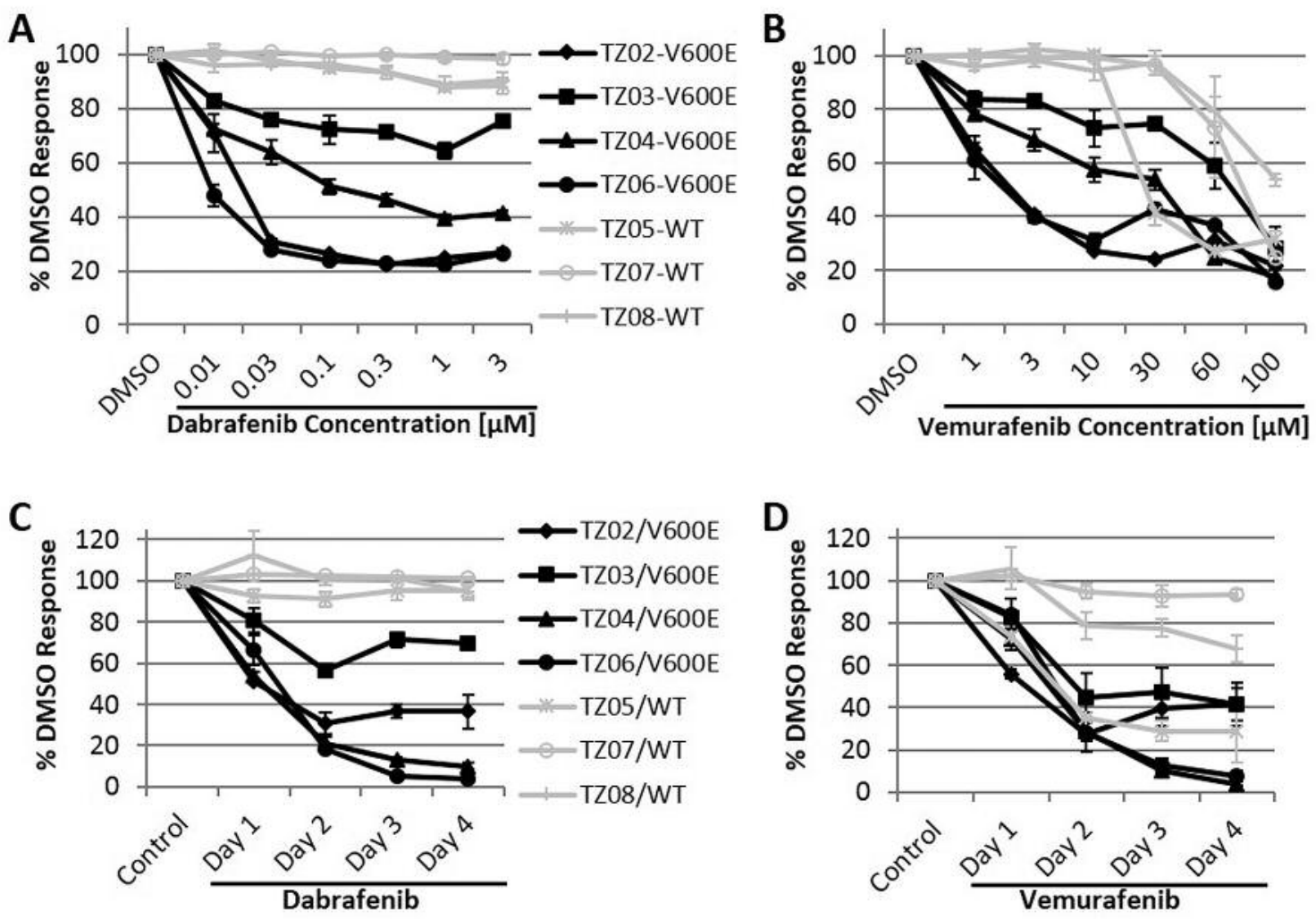

Figure 1. Primary human melanoma cell survival responses to BRAF inhibitors. WT and mutant V600E BRAF melanoma cell lines were exposed to increasing concentrations of $(A)$ dabrafenib and $(B)$ vemurafenib, and the WST-1 responses were measured following 2 days of drug treatment. Melanoma cell lines treated with (C) $1 \mu M$ dabrafenib and (D) $60 \mu M$ vemurafenib were also examined at the indicated time points. Data are presented as mean \pm SEM of 2 to 4 separate experiments performed in duplicate.

results of the BRAF inhibitor dose-response and time course experiments, melanoma cell lines were treated with a combination of drugs and varying doses of ionizing radiation $(0,2,6$, and $10 \mathrm{~Gy})$. The MEK inhibitors trametinib and cobimetinib were also tested alone and in combination with BRAF inhibitors according to their use as a clinical treatment for melanoma patients, i.e. vemurafanib with cobimetinib, or dabrafenib with trametinib. Results from the representative cell lines TZ03 (for mutant V600E BRAF) and TZ07 (for WT BRAF) are illustrated in Figures 2,3 and 4 .

All mutant V600E BRAF melanoma lines tested were sensitive to BRAF inhibitors, MEK inhibitors, and the combination treatments in the WST-1 assay (Figures 1 and 2). WT BRAF cell lines were less sensitive to BRAF inhibitors than the mutant BRAF cell lines, with the exception of TZ05, which was inhibited by vemurafenib (Figure 1). MEK inhibitors and the combination BRAF inhibitor/MEK inhibitor treatments suppressed the WT BRAF cell lines in a manner similar to the mutant $B R A F$ cell lines (Figure 2). In all cell lines tested, the responses to combination BRAF inhibitor/MEK inhibitor treatment were similar to the responses to MEK inhibitor alone (Figure 2).

Regardless of BRAF mutation status, all melanoma cell lines tested were radio-resistant (Figure 2). For cell lines that were sensitive to vemurafenib or dabrafenib, BRAF inhibitor treatment alone inhibited cell survival better than radiation alone (Figure 2). MEK inhibitor treatment suppressed cell survival more than radiation in all cell lines (Figure 2).

To test for a synergistic effect of BRAF inhibitors and ionizing radiation, the WST-1 response of cells to radiation was compared with the response to radiation following drug treatment. Although the mutant V600E BRAF cell lines had a reduced cell survival in the presence of BRAF inhibitor plus radiation compared with radiation alone (Figure $2 \mathrm{~A}$ ), this effect was not synergistic because it was similar to the response to BRAF inhibitor treatment alone. All cell lines tested had reduced cell survival in the presence of radiation plus a MEK inhibitor (with or without a BRAF inhibitor) compared with radiation alone, but this effect was also not additive because it was similar to MEK inhibitor treatment alone (Figure 2). 
A

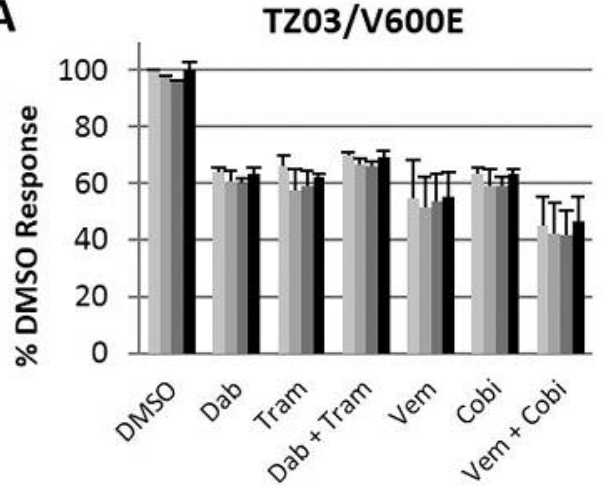

B

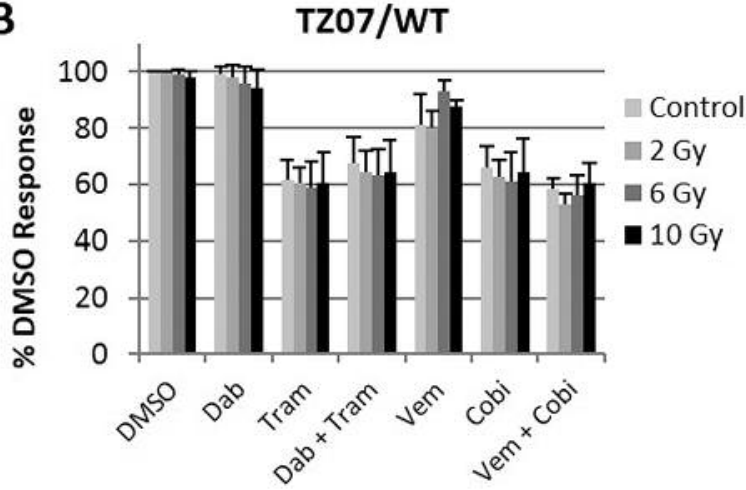

Figure 2. WST-1 cell survival responses of melanoma cell lines to radiation, BRAF inhibitors, and MEK inhibitors. Mutant V600E BRAF (A) and WT BRAF (B) melanoma cell lines were treated with vemurafenib, dabrafenib, trametinib, cobimetinib, vemurafenib plus cobimetinib, or dabrafenib plus trametinib prior to radiation at 0,2, 6, or $10 \mathrm{~Gy}$. Data are presented as mean \pm SEM of 3 separate experiments performed in duplicate. A twoway ANOVA was conducted on the influence of drug and radiation on cell survival. The effect of drugs ( $p<0.05)$, but not radiation or the interaction effect, was statistically significant for all cell types.

A

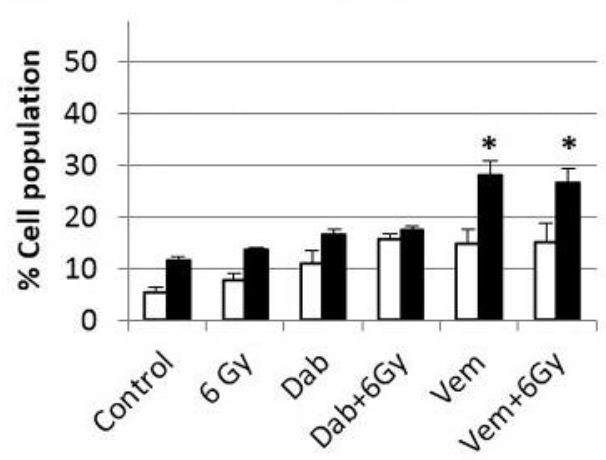

B

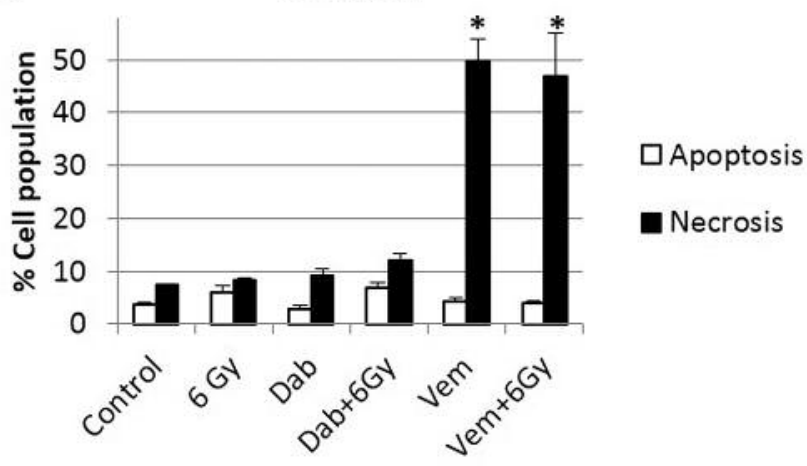

Figure 3. Melanoma cell death responses to BRAF inhibitors and radiation. Mutant V600E BRAF (A) and WT BRAF (B) melanoma cell lines were treated with vemurafenib or dabrafenib followed by 0 or 6 Gy radiation, and early apoptosis and necrosis were measured by flow cytometry. Annexin ${ }^{+} /$propidium iodide ${ }^{-}$singlet events (white) and propidium iodide ${ }^{+}$singlet events (black) as a percent of the total cell population are shown as mean \pm SEM of 3 separate experiments. Asterisks indicate statistical significance compared with corresponding control $(* p<0.05$ in a one-way ANOVA followed by a Bonferroni post-hoc test).

Dabrafenib and vemurafenib did not alter the melanoma cell death response to radiation. The cell death profile was analyzed by annexin ${ }^{+} /$propidium iodide $^{-}$staining for early apoptosis and by propidium iodide ${ }^{+}$staining for necrosis in the melanoma cell lines following treatment with the BRAF inhibitors vemurafenib or dabrafenib, $6 \mathrm{~Gy}$ radiation, or a combination of BRAF inhibitor plus radiation. Radiation alone did not increase apoptotic or necrotic cell death in all cell lines tested (Figure 3). Dabrafenib treatment significantly increased apoptotic, as well as necrotic cell death in the mutant V600E BRAF cell line TZ06, but not in the other cell lines (Figure 3 and data not shown). Vemurafenib significantly increased necrosis in all of the melanoma cell lines, except TZ04, regardless of BRAF status, but it did not alter apoptosis (Figure 3 and data not shown).

The cell death responses to BRAF inhibitor treatment plus radiation were not significantly different from the responses to BRAF inhibitor alone (Figure 3). Taken together, these results suggest that BRAF inhibitors do not sensitize melanoma cells to radiation.

Radiation and BRAF inhibitors independently induced cellcycle arrest in melanoma cells. To determine whether BRAF inhibitors and radiation induce changes in the primary 
A

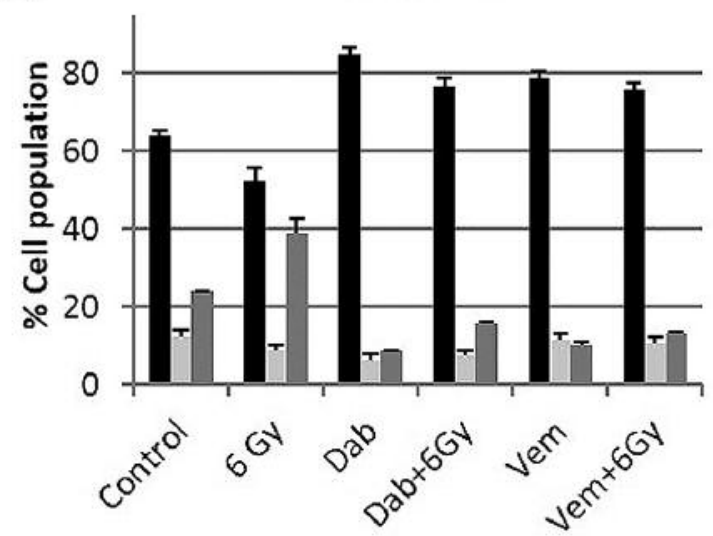

B

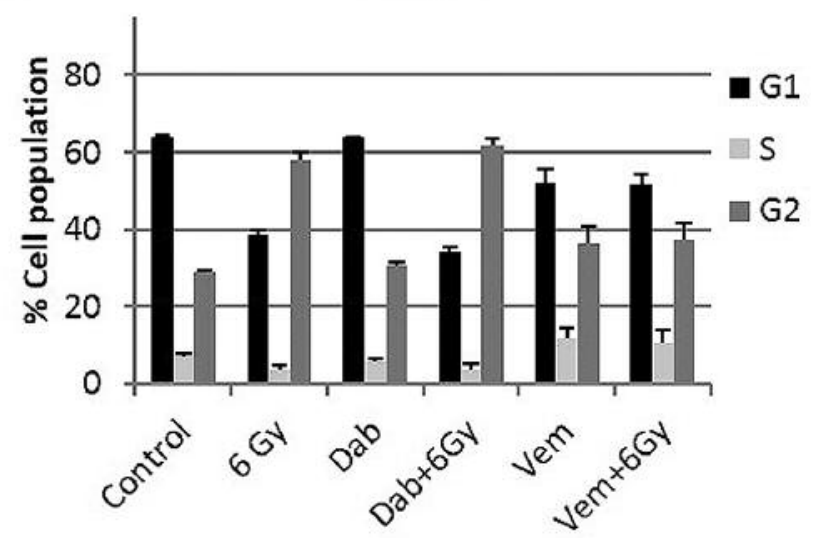

Figure 4. Cell-cycle analyses of melanoma cell lines following treatment with BRAF inhibitors and radiation. Mutant V600E BRAF (A) and WT $B R A F(B)$ melanoma cell lines were treated with vemurafenib or dabrafenib followed by 0 or 6 Gy radiation, and the cell cycle was assessed. Data are presented as mean $\pm S E M$ of 3 separate experiments.

melanoma cell cycle, WT and mutant V600E BRAF melanoma cell lines were treated with drugs or vehicle followed by $6 \mathrm{~Gy}$ radiation. The cell cycle was examined in fixed cells by propidium iodide labeling and analyzed by flow cytometry 24 hours post-irradiation. As shown in Figure 4 , radiation increased $G_{2}$ cell-cycle arrest in all melanoma cell lines.

Dabrafenib increased $G_{1}$ cell-cycle arrest in all the mutant V600E BRAF cell lines (Figure $4 \mathrm{~A}$ ). Vemurafenib increased $\mathrm{G}_{1}$ arrest in TZ02, TZ03, TZ04, and TZ05 and $\mathrm{G}_{2}$ arrest in TZ06 and TZ07 (Figure 4 and data not shown).

BRAF inhibitor treatment prior to radiation led to a cell cycle profile similar to BRAF inhibitor alone in melanoma lines that were sensitive to BRAF inhibitors in this assay (Figure 4). For cell lines that were not sensitive to BRAF inhibitors, the combination treatment of BRAF inhibitor plus radiation yielded a cell cycle profile similar to radiation alone (Figure 4B).

\section{Discussion}

The results presented here show that dabrafenib rapidly and selectively inhibited cell survival of primary human mutant V600E $B R A F$ melanoma cell lines, and that vemurafenib inhibited mutant $B R A F$ as well as some WT BRAF melanoma lines. All cell lines tested were resistant to $10 \mathrm{~Gy}$ of ionizing radiation. BRAF inhibitor plus ionizing radiation did not inhibit cell survival better than either treatment alone in any of the cell lines tested. Although vemurafenib increased necrotic cell death in 6 of the 7 melanoma lines, it had no effect on apoptosis. Dabrafenib only increased necrotic and apoptotic cell death in the mutant V600E BRAF line TZ06. These discrepancies between dabrafenib and vemurafenib may be due to the higher specificity of dabrafenib to mutant BRAF compared to vemurafenib, which also binds WT BRAF and CRAF $(15,16)$. We found that radiation and BRAF inhibitors induced varying but independent effects on cell cycle arrest. No synergistic or additive effects of BRAF inhibitors and radiation were observed in any of the assays. Based on the results presented here, we would expect that the antitumor effects of BRAF inhibitors and radiotherapy are not enhanced by concomitant use.

A previous in vitro study has shown that vemurafenib can induce radiosensitization in mutant $B R A F$ cancer cell lines. Radiosensitivity was observed in 4 melanoma cell lines harboring the V600E BRAF mutation, but not in WT lines, when treated with vemurafenib and ionizing radiation in a colony-forming assay (17). Differences in results may be due to the individual nature of human tumor cell lines, the passage number at which the cell lines were used, as well as the assays. A colony-forming assay will discriminate between cells that are senescent, which are generally detected as dying in shorter-term assays, versus cells that have been damaged and no longer have the ability to replicate (also detected as dying in shorter-term assays). Since we did not observe any short-term additive effects with BRAF inhibitors plus radiation on cell survival, cell death, or cell cycle, no longerterm additive effects are expected with these experimental conditions. An additive effect of the BRAF inhibitor PLX4720 and ionizing radiation was also observed in various mutant V600E BRAF cancer cell lines but not in WT lines $(18,19)$. However, these studies are difficult to compare with ours, as they did not use dabrafenib or vemurafenib, and they only included one melanoma cell line. 
In summary, our data suggest that the BRAF inhibitors dabrafenib and vemurafenib do not synergize with ionizing radiation to inhibit the growth of primary human melanoma cells. Neither synergistic nor additive effects of BRAF inhibition and ionizing radiation were observed in assays of cell survival, cell death, and cell cycle. Although BRAF inhibitors may lead to radiosensitivity side-effects in patients, our study does not support the possibility that this may carry over into a potential treatment regimen in melanoma.

\section{Acknowledgements}

The Authors thank Waltraud Froehlich for excellent technical support, Regine Schneider-Stock for BRAF sequencing, Luitpold Distel for use of the radiation chamber, and Gerold Schuler for general support. This work was supported by Novartis Pharma $\mathrm{GmbH}$ (Nuremberg, Germany) and the German Federal Ministry of Education and Research (BMBF).

\section{References}

1 Davies H, Bignell GR, Cox C, Stephens P, Edkins S, Clegg S, Teague J, Woffendin H, Garnett MJ, Bottomley W, Davis N, Dicks E, Ewing R, Floyd Y, Gray K, Hall S, Hawes R, Hughes J, Kosmidou V, Menzies A, Mould C, Parker A, Stevens C, Watt S, Hooper S, Wilson R, Jayatilake H, Gusterson BA, Cooper C, Shipley J, Hargrave D, Pritchard-Jones K, Maitland N, Chenevix-Trench G, Riggins GJ, Bigner DD, Palmieri G, Cossu A, Flanagan A, Nicholson A, Ho JW, Leung SY, Yuen ST, Weber BL, Seigler HF, Darrow TL, Paterson H, Marais R, Marshall CJ, Wooster R, Stratton MR and Futreal PA: Mutations of the BRAF gene in human cancer. Nature 417: 949-954, 2002.

2 Heinzerling L, Baiter M, Kühnapfel S, Schuler G, Keikavoussi P, Agaimy A, Kiesewetter F, Hartmann A and Schneider-Stock $\mathrm{R}$ : Mutation landscape in melanoma patients clinical implications of heterogeneity of BRAF mutations. Br J Cancer 109: 2833-2841, 2013.

3 Kim BA, Jee HG, Yi JW, Kim SJ, Chai YJ, Choi JY and Lee KE: Expression profiling of a human thyroid cell line stably expressing the BRAFV600E mutation. Cancer Genomics Proteomics 14: 53-68, 2017.

4 Jakob JA, Bassett RL Jr., Ng CS, Curry JL, Joseph RW, Alvarado GC, Rohlfs ML, Richard J, Gershenwald JE, Kim KB, Lazar AJ, Hwu P and Davies MA: NRAS mutation status is an independent prognostic factor in metastatic melanoma. Cancer 118: 4014-4023, 2012.

5 Heinzerling L, Kühnapfel S, Meckbach D, Baiter M, Kaempgen E, Keikavoussi P, Schuler G, Agaimy A, Bauer J, Hartmann A, Kiesewetter F and Schneider-Stock R: Rare BRAF mutations in melanoma patients: implications for molecular testing in clinical practice. Br J Cancer 108: 2164-2171, 2013.

6 Ponti G, Manfredini M, Greco S, Pellacani G, Depenni R, Tomasi A, Maccaferri M and Cascinu S: BRAF, NRAS and CKIT advanced melanoma: clinico-pathological features, targetedtherapy strategies and survival. Anticancer Res 37: 7043-7048, 2017.
7 Rapi V, Dogan A, Schultheis B, Hartmann F, Rezniczek GA, Tempfer CB: Melanoma of the Vagina: Case report and systematic review of the literature. Anticancer Res 37: 69116920, 2017.

8 Joseph EW, Pratilas CA, Poulikakos PI, Tadi M, Wang W, Taylor BS, Halilovic E, Persaud Y, Xing F, Viale A, Tsai J, Chapman PB, Bollag G, Solit DB and Rosen N: The RAF inhibitor PLX4032 inhibits ERK signaling and tumor cell proliferation in a V600E BRAF-selective manner. Proc Natl Acad Sci USA 107: 14903-14908, 2010.

9 Laquerre S, Arnone M, Moss K, Yang J, Fisher K, Kane-Carson LS, Smitheman K, Ward J, Heidrich B, Rheault T, Adjabeng G, Hornberger K, Stellwagen J, Waterson A, Han C, Mook RA Jr., Uehling D and King AJ: A selective Raf kinase inhibitor induces cell death and tumor regression of human cancer cell lines encoding B-RafV600E mutation. Mol Cancer Ther 8(Suppl 1): B88-B88, 2009.

10 Chapman PB, Hauschild A, Robert C, Haanen JB, Ascierto P, Larkin J, Dummer R, Garbe C, Testori A, Maio M, Hogg D, Lorigan P, Lebbe C, Jouary T, Schadendorf D, Ribas A, O'Day SJ, Sosman JA, Kirkwood JM, Eggermont AM, Dreno B, Nolop K, Li J, Nelson B, Hou J, Lee RJ, Flaherty KT, McArthur GA and BRIM-3 Study Group: Improved survival with vemurafenib in melanoma with BRAF V600E mutation. N Engl J Med 364: 2507-2516, 2011.

11 Sosman JA, Kim KB, Schuchter L, Gonzalez R, Pavlick AC, Weber JS, McArthur GA, Hutson TE, Moschos SJ, Flaherty KT, Hersey P, Kefford R, Lawrence D, Puzanov I, Lewis KD, Amaravadi RK, Chmielowski B, Lawrence HJ, Shyr Y, Ye F, Li J, Nolop KB, Lee RJ, Joe AK and Ribas A: Survival in BRAF V600-mutant advanced melanoma treated with vemurafenib. N Engl J Med 366: 707-714, 2012.

12 Hauschild A, Grob JJ, Demidov LV, Jouary T, Gutzmer R, Millward M, Rutkowski P, Blank CU, Miller WH Jr., Kaempgen E, Martín-Algarra S, Karaszewska B, Mauch C, Chiarion-Sileni V, Martin AM, Swann S, Haney P, Mirakhur B, Guckert ME, Goodman V and Chapman PB: Dabrafenib in BRAF-mutated metastatic melanoma: a multicentre, open-label, phase 3 randomised controlled trial. Lancet 380: 358-365, 2012.

13 Najem A, Krayem M, Perdrix A, Kerger J, Awada A, Journe F and Ghanem G: New Drug Combination Strategies in Melanoma: Current Status and Future Directions. Anticancer Res 37: 5941-5953, 2017.

14 Hecht M, Zimmer L, Loquai C, Weishaupt C, Gutzmer R, Schuster B, Gleisner S, Schulze B, Goldinger SM, Berking C, Forschner A, Clemens P, Grabenbauer G, Müller-Brenne T, Bauch J, Eich HT, Grabbe S, Schadendorf D, Schuler G, Keikavoussi P, Semrau S, Fietkau R, Distel LV and Heinzerling L: Radiosensitization by BRAF inhibitor therapy - mechanism and frequency of toxicity in melanoma patients. Ann Oncol 26: 1238-1244, 2015.

15 Kefford R, Arkenau H, Brown MP, Millward M, Infante JR, Long GV, Ouellet D, Curtis M, Lebowitz PF and Falchook GS: Phase I/II study of GSK2118436, a selective inhibitor of oncogenic mutant BRAF kinase, in patients with metastatic melanoma and other solid tumors. J Clin Oncol 28(Suppl 15): 8503-8503, 2010.

16 Bollag G, Hirth P, Tsai J, Zhang J, Ibrahim PN, Cho H, Spevak W, Zhang C, Zhang Y, Habets G, Burton EA, Wong B, Tsang G, West BL, Powell B, Shellooe R, Marimuthu A, Nguyen H, 
Zhang KY, Artis DR, Schlessinger J, Su F, Higgins B, Iyer R, D'Andrea K, Koehler A, Stumm M, Lin PS, Lee RJ, Grippo J, Puzanov I, Kim KB, Ribas A, McArthur GA, Sosman JA, Chapman PB, Flaherty KT, Xu X, Nathanson KL and Nolop K: Clinical efficacy of a RAF inhibitor needs broad target blockade in BRAF-mutant melanoma. Nature 467: 596-599, 2010.

17 Sambade MJ, Peters EC, Thomas NE, Kaufmann WK, Kimple RJ and Shields JM: Melanoma cells show a heterogeneous range of sensitivity to ionizing radiation and are radiosensitized by inhibition of BRAF with PLX-4032. Radiother Oncol 98: 394399, 2011.

18 Dasgupta T, Haas-Kogan DA, Yang X, Olow A, Yang DX, Gragg A, Orloff LA and Yom SS: Genotype-dependent cooperation of ionizing radiation with BRAF inhibition in BRAF V600Emutated carcinomas. Invest New Drugs 31: 1136-1141, 2013.

19 Dasgupta T, Olow AK, Yang X, Hashizume R, Nicolaides TP, Tom M, Aoki Y, Berger MS, Weiss WA, Stalpers LJ, Prados M, James CD, Mueller S and Haas-Kogan DA: Survival advantage combining a BRAF inhibitor and radiation in BRAF V600Emutant glioma. J Neurooncol 126: 385-393, 2016.
20 Funck-Brentano E, Alvarez JC, Longvert C, Abe E, Beauchet A, Funck-Brentano $\mathrm{C}$ and Saiag P: Plasma vemurafenib concentrations in advanced BRAFV600mut melanoma patients: impact on tumour response and tolerance. Ann Oncol 26: 1470-1475, 2015.

21 European Medicines Agency. 2013 Committee for Medicinal Products for Human Use assessment report Tafinlar. EMA/ CHMP/242419/2013.

22 GlaxoSmithKline. 2013 GSK1120212 + GSK2118436 Investigator's Brochure. 2011N126811_01.

23 U.S. Food and Drug Administration. 2015 Genentech Cotellic Reference ID: 3845167.

Received December 21, 2017

Revised January 31, 2018

Accepted February 1, 2018 